\title{
Oscillation criteria for a certain second-order nonlinear perturbed differential equations
}

Pakize Temtek $^{1 *}$ and Aydin Tiryaki ${ }^{2}$

"Correspondence:

temtek@erciyes.edu.tr

${ }^{1}$ Department of Mathematics,

Faculty of Science, Erciyes

University, Kayseri, Turkey

Full list of author information is

available at the end of the article

\begin{abstract}
In this paper, a class of second-order nonlinear perturbed differential equation and its special cases are studied. By using the generalized Riccati transformation and well-known techniques, some new oscillation criteria are established. The results obtained essentially generalize and improve some known results and can be applied to the well-known half-linear and damped half-linear-type equations.
\end{abstract}

\section{Introduction}

This paper is concerned with the problem of oscillatory behavior of the perturbed secondorder nonlinear differential equation

$$
\left(r(t) \psi(u)\left|u^{\prime}(t)\right|^{\alpha-1} u^{\prime}(t)\right)^{\prime}+Q(t, u)=P\left(t, u, u^{\prime}\right)
$$

where $r \in C\left(I, \mathbb{R}^{+}\right), \psi \in C\left(\mathbb{R}, \mathbb{R}^{+}\right), \mathbb{R}=(-\infty, \infty), I=\left[t_{0}, \infty\right)$, and $\alpha$ is a positive real number. Throughout the paper, according to the results, we shall impose the following conditions:

$\left(\mathrm{H}_{1}\right)$ Let $f \in C^{\prime}(\mathbb{R}, \mathbb{R})$, and there exists a constant $k>0$ such that $\frac{f^{\prime}(x)}{\left(\left.\psi(x) f(x)\right|^{\alpha-1}\right)^{\frac{1}{\alpha}}} \geq k$ and $f(x) x>0$ for $x \neq 0$,

$\left(\mathrm{H}_{2}\right) Q \in C(I \times \mathbb{R}, \mathbb{R})$, and there exists a continuous function $q(t)$ such that $\frac{Q(t, x)}{f(x)} \geq q(t)$ for $x \neq 0$,

$\left(\mathrm{H}_{3}\right) \quad P \in C(I \times \mathbb{R} \times \mathbb{R}, \mathbb{R})$, and there exists a continuous function $p(t)$ such that $\frac{P(t, x, y)}{f(x)} \leq p(t)$ for $x \neq 0, y \neq 0$,

$\left(\mathrm{H}_{4}\right) P \in C(I \times \mathbb{R} \times \mathbb{R}, \mathbb{R})$, and there exists a continuous function $p(t)$ such that $\frac{P(t, x, y)}{f(x)} \leq$ $p(t) \frac{\mid y^{\alpha-1} y}{f(x)}$ for $x \neq 0, y \neq 0$,

$\left(\mathrm{H}_{5}\right) \int_{\epsilon}^{\infty}\left(\frac{\psi(y)}{f(y)}\right)^{\frac{1}{\alpha}} d y<\infty$ and $\int_{-\epsilon}^{-\infty}\left(\frac{\psi(y)}{f(y)}\right)^{\frac{1}{\alpha}} d y<\infty$ for every $\epsilon>0$.

By a solution of (1), we mean a function $u \in C^{\prime}\left(\left[T_{u}, \infty\right), \mathbb{R}\right), T_{u} \geq t_{0}$, which has the property $r(t)\left|u^{\prime}(t)\right|^{\alpha-1} u^{\prime}(t) \in C^{\prime}\left(\left[T_{u}, \infty\right), \mathbb{R}\right)$ and satisfies $(1)$ on $\left[T_{u}, \infty\right)$. We consider only those solutions $u(t)$ of (1), which satisfy $\sup \left\{|u(t)|: t \geq T_{u}\right\}>0$ for all $T_{u} \geq t_{0}$. We assume that (1) possesses such a solution. A nontrivial solution of (1) is said to be oscillatory if it has a sequence of zeros tending to infinity, otherwise, it is called nonoscillatory. An equation is said to be oscillatory if all its solutions are oscillatory.

In the last century, oscillation theory of differential equations has developed quickly and played an important role in qualitative theory of differential equations and theory of

\section{Springer}

@2013 Temtek and Tiryaki; licensee Springer. This is an Open Access article distributed under the terms of the Creative Commons Attribution License (http://creativecommons.org/licenses/by/2.0), which permits unrestricted use, distribution, and reproduction in any medium, provided the original work is properly cited. 
boundary value problem. The study of oscillation theory plays an important role in physical science and technology; for example in the oscillation of building or machine, electromagnetic vibration in radio technology and optical science, self-exited vibration in control system, sound vibration, beam vibration in synchrotron accelerator, the vibration sparked for burning rocket engine, the complicated oscillation in chemical reaction, and also in the research of a lossless high-speed computer network and physical sciences [1, 2]. All of this different phenomena can be unified into oscillation theory through an oscillation equation. There are many books on oscillation theory, we choose to refer to [3-6].

This problem has received the attention of many authors. Many criteria have been found, some of which involve the average behavior of the integral of the alternating coefficient. Among numerous papers dealing with this subject, we refer in particular to [7-35].

The first attempt for Equation (1) was due to Graef et al. [13], who investigated the case of (1) with $\alpha=1$ and $\psi(u) \equiv 1$. In 1996, Wong and Agarwal studied the oscillatory behavior of (1) with $\psi(u) \equiv 1$ and the existence of a positive monotone solution of the damped equation given in [33]. Note that their paper contains a lot of new results and has been the motivation for the work for many others. It is the motivation for two recent papers and this work. In [2], Zhang and Wang studied the oscillation of Equation (1) with $\alpha=1$. We should note that Wong's [33] result for $\alpha=1$ corresponds to the special case with $\psi(u) \equiv 1$ in two main results in [2]. On the other hand, in another recent paper, Remili [22] studied the oscillation results for Equation (1) with $\alpha=1, \psi(u) \equiv 1$. Two results of Remili, are also similar to Wong's results with addition of a suitable weighted function.

In this paper, motivated by the ideas in [33], we obtain several new oscillation criteria for Equation (1) and its special cases by using generalized Riccati transformation and well known techniques. The results obtained essentially generalize and improve some known results and can be applied to the well-known half-linear equation and damped half-lineartype equations.

\section{Main results}

In this section, we prove our main results.

Theorem 2.1 Let conditions $\left(\mathrm{H}_{1}\right),\left(\mathrm{H}_{2}\right)$ and $\left(\mathrm{H}_{3}\right)$ hold. If there exists a differentiable function $\rho: I \rightarrow \mathbb{R}^{+}$such that $\rho^{\prime}(t) \geq 0$,

$$
\lim _{t \rightarrow \infty} \int_{t_{0}}^{t}\left(\frac{1}{\rho^{\alpha}(s) r(s)}\right)^{\frac{1}{\alpha}} d s=\infty
$$

and

$$
\limsup _{t \rightarrow \infty} \int_{t_{0}}^{t} A(s) d s=\infty
$$

where

$$
A(t)=\rho^{\alpha}(t)\left[q(t)-p(t)-\mu r(t)\left(\frac{\rho^{\prime}(t)}{\rho(t)}\right)^{\alpha+1}\right] \text { and } \mu:=\left(\frac{\alpha}{\alpha+1}\right)^{\alpha+1}\left(\frac{\alpha}{k}\right)^{\alpha}
$$

then Equation (1) is oscillatory. 
Proof Let $u(t)$ be a nonoscillatory solution of (1). We may assume that $u(t)>0$ for $t \geq t_{1} \geq$ $t_{0}$. The proof in the case $u(t)<0$ for $t \geq t_{1}$ is similar, and hence omitted. Define

$$
w(t)=\rho^{\alpha}(t) \frac{r(t) \psi(u(t))\left|u^{\prime}(t)\right|^{\alpha-1} u^{\prime}(t)}{f(u(t))} .
$$

Differentiating (5) and making use of (1) and from hypotheses $\left(\mathrm{H}_{2}\right)$ and $\left(\mathrm{H}_{3}\right)$, it follows that

$$
w^{\prime}(t) \leq \frac{\alpha \rho^{\prime}(t)}{\rho(t)}|w(t)|-\rho^{\alpha}(t)(q(t)-p(t))-\frac{\rho^{\alpha}(t) r(t) \psi(u(t))\left|u^{\prime}(t)\right|^{\alpha-1} u^{\prime 2}(t) f^{\prime}(u(t))}{f^{2}(u(t))} .
$$

It is easy to see that condition $\left(\mathrm{H}_{1}\right)$ implies that

$$
w^{\prime}(t) \leq \frac{\alpha \rho^{\prime}(t)}{\rho(t)}|w(t)|-\rho^{\alpha}(t)(q(t)-p(t))-k \frac{|w(t)|^{\frac{\alpha+1}{\alpha}}}{\rho(t)(r(t))^{\frac{1}{\alpha}}} .
$$

By using the extremum of one variable function it can be easily proved that

$$
D X-E X^{\frac{\alpha+1}{\alpha}} \leq \frac{\alpha^{\alpha}}{(\alpha+1)^{\alpha+1}} D^{\alpha+1} E^{-\alpha}, \quad D \geq 0, E>0, X \geq 0 .
$$

Using the above inequality, we get

$$
w^{\prime}(t) \leq-\rho^{\alpha}(t)\left[q(t)-p(t)-\mu r(t)\left(\frac{\rho^{\prime}(t)}{\rho(t)}\right)^{\alpha+1}\right]
$$

Integrating this inequality from $t_{1}$ to $t$, we get

$$
w(t) \leq w\left(t_{1}\right)-\int_{t_{1}}^{t} \rho^{\alpha}(s)\left[q(s)-p(s)-\mu r(s)\left(\frac{\rho^{\prime}(s)}{\rho(s)}\right)^{\alpha+1}\right] d s, \quad t \geq t_{1} \geq t_{0} .
$$

Letting $\lim \sup _{t \rightarrow \infty}$, we get in view of (3) that $w(t) \rightarrow-\infty$. Hence there exists $t_{2} \geq t_{1}$ such that $u^{\prime}(t)<0$ for $t \geq t_{2}$. Condition (3) also implies

$$
\int_{t_{0}}^{\infty} \rho^{\alpha}(s)(q(s)-p(s)) d s=\infty
$$

and there exists $t_{3} \geq t_{2}$ such that

$$
\int_{t_{3}}^{t} \rho^{\alpha}(s)(q(s)-p(s)) d s \geq 0
$$

for $t \geq t_{3}$. Now multiplying (1) by $\rho^{\alpha}(t)$ and integrating by parts, we obtain

$$
\begin{aligned}
-\rho^{\alpha}(t)\left(r(t) \psi(u(t))\left(-u^{\prime}(t)\right)^{\alpha}\right)^{\prime} \leq & -\rho^{\alpha}(t)(q(t)-p(t)) f(u(t)), \\
-\rho^{\alpha}(t) r(t) \psi(u(t))\left(-u^{\prime}(t)\right)^{\alpha}+c_{t_{3}} \leq & -\int_{t_{3}}^{t}\left(\rho^{\alpha}(s)\right)^{\prime} r(s) \psi(u(s))\left(-u^{\prime}(s)\right)^{\alpha} d s \\
& -\int_{t_{3}}^{t} \rho^{\alpha}(s)(q(s)-p(s)) f(u(s)) d s,
\end{aligned}
$$


where $c_{t_{3}}:=\rho^{\alpha}\left(t_{3}\right) r\left(t_{3}\right) \psi\left(u\left(t_{3}\right)\right)\left(-u^{\prime}\left(t_{3}\right)\right)^{\alpha}>0$. Then

$$
\begin{aligned}
& \rho^{\alpha}(t) r(t) \psi(u(t))\left(-u^{\prime}(t)\right)^{\alpha} \\
& \geq c_{t_{3}}+\int_{t_{3}}^{t}\left(\rho^{\alpha}(s)\right)^{\prime} r(s) \psi(u(s))\left(-u^{\prime}(s)\right)^{\alpha} d s \\
& +\int_{t_{3}}^{t} \rho^{\alpha}(s)(q(s)-p(s)) f(u(s)) d s \\
& \geq c_{t_{3}}+\int_{t_{3}}^{t} \rho^{\alpha}(s)(q(s)-p(s)) f(u(s)) d s \\
& =c_{t_{3}}+f(u(t)) \int_{t_{3}}^{t} \rho^{\alpha}(s)(q(s)-p(s)) d s \\
& -\int_{t_{3}}^{t} f^{\prime}(u(s)) u^{\prime}(s) \int_{t_{3}}^{s} \rho^{\alpha}(v)(q(v)-p(v)) d v d s, \\
& \rho^{\alpha}(t) r(t) \psi(u(t))\left(-u^{\prime}(t)\right)^{\alpha} \geq c_{t_{3}}, \\
& \psi(u(t))\left(-u^{\prime}(t)\right)^{\alpha} \geq \frac{c_{t_{3}}}{\rho^{\alpha}(t) r(t)}, \\
& (\psi(u(t)))^{\frac{1}{\alpha}}\left(-u^{\prime}(t)\right) \geq\left(\frac{c_{t_{3}}}{\rho^{\alpha}(t) r(t)}\right)^{\frac{1}{\alpha}}, \\
& \int_{t_{3}}^{t}(\psi(u(s)))^{\frac{1}{\alpha}} u^{\prime}(s) d s \leq-\left(c_{t_{3}}\right)^{\frac{1}{\alpha}} \int_{t_{3}}^{t}\left(\frac{1}{\rho^{\alpha}(s) r(s)}\right)^{\frac{1}{\alpha}} d s, \\
& \int_{u\left(t_{3}\right)}^{u(t)}(\psi(y))^{\frac{1}{\alpha}} d y \leq-\left(c_{t_{3}}\right)^{\frac{1}{\alpha}} \int_{t_{3}}^{t}\left(\frac{1}{\rho^{\alpha}(s) r(s)}\right)^{\frac{1}{\alpha}} d s .
\end{aligned}
$$

Noting condition (2), and the fact that $0<u(t) \leq u\left(t_{3}\right)$, this implies that the left-hand side of this inequality, that is, $\int_{u\left(t_{3}\right)}^{u(t)}(\psi(y))^{\frac{1}{\alpha}} d y$ is lower bounded. But the right-hand side of it tend towards mines infinite, so contradiction exists. The proof is complete.

Example 2.1 Consider the differential equations of the form

$$
\begin{aligned}
& \left(r(t) \psi(u)\left|u^{\prime}\right|^{\alpha-1} u^{\prime}\right)^{\prime}+\left[\frac{3}{2} t^{\frac{-3}{2}}(2+\cos t)+\theta_{1}(t, u)\right] f(u) \\
& =\left(t^{\frac{-1}{2}} \sin t+t^{-3} \theta_{2}\left(t, u, u^{\prime}\right)\right) f(u), \quad t \geq t_{0},
\end{aligned}
$$

where $\theta_{1}$ and $\theta_{2}$ are continuous functions such that $\theta_{1}(t, u) \geq 0$ and $\theta_{2}\left(t, u, u^{\prime}\right) \leq 1$. If we take the functions $r, \psi, f$ and the constant $\alpha>0$ satisfying the condition of Theorem 2.1, then Equation $(\mathrm{E})$ is oscillatory. In particular, for the equation

$$
\left(\left|u^{\prime}\right| u^{\prime}\right)^{\prime}+\left[\frac{3}{2} t^{\frac{-3}{2}}(2+\cos t)+t e^{u}\right] u^{3}=\left(t^{\frac{-1}{2}} \sin t+t^{-3} \frac{u^{3} \cos u^{\prime}}{u^{2}+1}\right) u^{3}, \quad t \geq \frac{\pi}{2}
$$

all conditions of Theorem 2.1 are satisfied. Hence it is oscillatory. 
A close look at the proof of Theorem 2.1 reveals that condition (3) may be replaced by the conditions

$$
\begin{aligned}
& \limsup _{t \rightarrow \infty} \int_{t_{0}}^{t} \rho^{\alpha}(s)[q(s)-p(s)] d s=\infty, \\
& \limsup _{t \rightarrow \infty} \int_{t_{0}}^{t} \rho^{\alpha}(s) r(s)\left(\frac{\rho^{\prime}(s)}{\rho(s)}\right)^{\alpha+1} d s<\infty .
\end{aligned}
$$

Corollary 2.1 Let the conditions of Theorem 2.1 be satisfied except that condition (3) is replaced by (12) and (13). Then Equation (1) is oscillatory.

Note that there is no restriction on the sign of functions $p(t)$ and $q(t)$. But we have the condition

$$
\int_{t_{0}}^{\infty} \rho^{\alpha}(s)(q(s)-p(s)) d s=\infty
$$

Now, supposing that this condition is not an establishment, we discuss the oscillatory behavior of (1). We have the following result.

Theorem 2.2 Let conditions $\left(\mathrm{H}_{1}\right),\left(\mathrm{H}_{2}\right),\left(\mathrm{H}_{3}\right)$ and $\left(\mathrm{H}_{5}\right)$ hold. Suppose that $\rho$ is a positive continuously differentiable function on the interval I such that $\rho^{\prime} \geq 0$ on I and (2) hold. If

$$
\begin{aligned}
& \int_{t_{0}}^{\infty} \rho^{\alpha}(t)[q(t)-p(t)] d t<\infty, \\
& \liminf _{t \rightarrow \infty}\left[\int_{t_{0}}^{t} A(s) d s\right] \geq 0
\end{aligned}
$$

and

$$
\lim _{t \rightarrow \infty} \int_{t_{0}}^{t}\left(\frac{1}{\rho^{\alpha}(s) r(s)} \int_{s}^{\infty} A(v) d v\right)^{\frac{1}{\alpha}} d s=\infty
$$

then Equation (1) is oscillatory.

Remark 2.1 Condition (15) implies that

$$
\int_{t_{0}}^{\infty} A(s) d s<\infty \text { and } \lim _{t \rightarrow \infty} \int_{t_{0}}^{t} A(s) d s=\int_{t_{0}}^{\infty} A(s) d s
$$

hence (16) takes the form $\int_{t_{0}}^{\infty} A(s) d s \geq 0$ for all large $T$.

Proof Let $u(t)$ be a nonoscillatory solution on the interval I of the differential Equation (1). We suppose, as in Theorem 2.1, that $u(t)$ is positive on I. We consider the following three cases for the behavior of $u^{\prime}(t)$.

Case 1: $u^{\prime}(t)>0$ for $t \geq t_{1}$ for some $t_{1} \geq t_{0}$. From (10), we have

$$
\int_{t_{1}}^{t} A(s) d s \leq w\left(t_{1}\right)-w(t)
$$


Hence, for all $t \geq t_{1}$

$$
\int_{t}^{\infty} A(s) d s \leq \rho^{\alpha}(t) \frac{r(t) \psi(u(t))\left(u^{\prime}(t)\right)^{\alpha}}{f(u(t))} .
$$

Using $\left(\mathrm{H}_{5}\right)$, we obtain

$$
\begin{aligned}
\int_{t_{1}}^{t}\left(\frac{1}{\rho^{\alpha}(s) r(s)} \int_{s}^{\infty} A(v) d v\right)^{\frac{1}{\alpha}} d s & \leq \int_{t_{1}}^{t}\left(\frac{\psi(u(s))}{f(u(s))}\right)^{\frac{1}{\alpha}} u^{\prime}(s) d s \\
& \leq \int_{u\left(t_{1}\right)}^{\infty}\left(\frac{\psi(y)}{f(y)}\right)^{\frac{1}{\alpha}} d y<\infty .
\end{aligned}
$$

This contradicts condition (17).

Case 2: $u^{\prime}(t)$ changes signs, then there exists a sequence $\left(\alpha_{n}\right) \rightarrow \infty$ in I such that $u^{\prime}\left(\alpha_{n}\right)<0$. Choose $N$ large enough, so that

$$
\int_{\alpha_{N}}^{\infty} A(s) d s \geq 0
$$

Then from (10), we have

$$
\begin{aligned}
& \frac{-\rho^{\alpha}(t) r(t) \psi(u(t))\left(-u^{\prime}(t)\right)^{\alpha}}{f(u(t))} \leq-C_{\alpha_{N}}-\int_{\alpha_{N}}^{t} A(s) d s, \\
& \liminf _{t \rightarrow \infty} \frac{\rho^{\alpha}(t) r(t) \psi(u(t))\left(-u^{\prime}(t)\right)^{\alpha}}{f(u(t))} \geq C_{\alpha_{N}}+\liminf _{t \rightarrow \infty} \int_{\alpha_{N}}^{t} A(s) d s>0,
\end{aligned}
$$

which contradicts the fact that $u^{\prime}(t)$ oscillates.

Case 3: $u^{\prime}(t)<0$ for $t \geq t_{1}$. Condition (16) implies that for any $t_{0} \geq t_{1}$, there exists $t_{1} \geq t_{0}$ such that

$$
\int_{t}^{\infty} \rho^{\alpha}(s)[q(s)-p(s)] d s \geq 0
$$

for all $t \geq t_{1}$ as it was shown in [28]. The remaining part of the proof is similar to that of Theorem 2.1.

Remark 2.2 When $\alpha=1$ and $\psi(u) \equiv 1$, Theorem 2.1 and Theorem 2.2 reduce to Theorem 1 and 2 in [22], respectively.

Theorem 2.3 Let conditions $\left(\mathrm{H}_{1}\right),\left(\mathrm{H}_{2}\right)$ and $\left(\mathrm{H}_{3}\right)$ hold. If there exists a differentiable function $\rho: I \rightarrow \mathbb{R}^{+}$such that $\rho^{\prime}(t) \geq 0$,

$$
\lim _{t \rightarrow \infty} \int_{t_{0}}^{t}\left(\frac{1}{R\left(s, t_{0}\right) \rho^{\alpha}(s) r(s)}\right)^{\frac{1}{\alpha}} d s=\infty
$$

and

$$
\limsup _{t \rightarrow \infty} \int_{t_{0}}^{t} B(s) d s=\infty,
$$


where

$$
\begin{aligned}
& R\left(t, t_{0}\right)=\int_{t_{0}}^{t} \frac{d s}{r(s) \rho^{\alpha}(s)} \\
& B(t)=R\left(t, t_{0}\right) \rho^{\alpha}(t)\left[q(t)-p(t)-\mu_{1} r(t)\left(\alpha \frac{\rho^{\prime}(t)}{\rho(t)}+\frac{1}{\rho^{\alpha}(t) r(t) R\left(t, t_{0}\right)}\right)^{\alpha+1}\right],
\end{aligned}
$$

then Equation (1) is oscillatory.

Proof Otherwise, $u(t) \neq 0$ for all $t \geq t_{1} \geq t_{0}$. Define

$$
w(t)=\rho^{\alpha}(t) \frac{r(t) \psi(u(t))\left|u^{\prime}(t)\right|^{\alpha-1} u^{\prime}(t)}{f(u(t))} R\left(t, t_{0}\right) .
$$

Differentiating (22) and making use of $(1)$ and conditions $\left(\mathrm{H}_{2}\right)$ and $\left(\mathrm{H}_{5}\right)$, it follows that

$$
\begin{aligned}
w^{\prime}(t) \leq & \frac{\alpha \rho^{\prime}(t)}{\rho(t)}|w(t)|-\rho^{\alpha}(t)(q(t)-p(t)) R\left(t, t_{0}\right) \\
& -\frac{\rho^{\alpha}(t) r(t) \psi(u(t))\left|u^{\prime}(t)\right|^{\alpha-1} u^{\prime 2}(t) f^{\prime}(u(t))}{f^{2}(u(t))} R\left(t, t_{0}\right)+\frac{\psi(u(t))\left|u^{\prime}(t)\right|^{\alpha-1} u^{\prime}(t)}{f(u(t))} .
\end{aligned}
$$

From $\left(\mathrm{H}_{1}\right)$ and using the equality

$$
\frac{\psi(u(t))\left|u^{\prime}(t)\right|^{\alpha}}{f(u(t))}=\frac{|w(t)|}{\rho^{\alpha}(t) r(t) R\left(t, t_{0}\right)},
$$

we get

$$
\begin{aligned}
w^{\prime}(t) \leq & \left(\frac{\alpha \rho^{\prime}(t)}{\rho(t)}+\frac{1}{\rho^{\alpha}(t) r(t) R\left(t, t_{0}\right)}\right)|w(t)|-\rho^{\alpha}(t)(q(t)-p(t)) R\left(t, t_{0}\right) \\
& -k \frac{|w(t)|^{1+\frac{1}{\alpha}}}{\rho(t) r(t)^{\frac{1}{\alpha}}\left(R\left(t, t_{0}\right)\right)^{\frac{1}{\alpha}}} .
\end{aligned}
$$

The rest of the proof can be made as in the proof of Theorem 2.1.

Theorem 2.4 Let conditions $\left(\mathrm{H}_{1}\right),\left(\mathrm{H}_{2}\right),\left(\mathrm{H}_{3}\right)$ and $\left(\mathrm{H}_{5}\right)$ hold. Suppose that there exists a differentiable function $\rho: I \rightarrow \mathbb{R}^{+}$such that $\rho^{\prime}(t) \geq 0$ on I and (18) hold. If

$$
\limsup _{t \rightarrow \infty} \int_{t_{0}}^{t} A(s) R\left(s, t_{0}\right) d s=\infty,
$$

then any solution $u(t)$ of Equation (1) such that $u^{\prime}(t)$ is bounded is oscillatory.

Proof Let $u(t)$ be nonoscillatory solution of (1), say $u(t)>0$ for $t \geq t_{0}$. Further, assume that $\left|u^{\prime}(t)\right| \leq L$ for some $L>0$. Beginning as in the proof of Theorem 2.3, we have

$$
\begin{aligned}
w^{\prime}(t) \leq & \frac{\alpha \rho^{\prime}(t)}{\rho(t)}|w(t)|-\rho^{\alpha}(t)(q(t)-p(t)) R\left(t, t_{0}\right) \\
& -\frac{\rho^{\alpha}(t) r(t) \psi(u(t))\left|u^{\prime}(t)\right|^{\alpha-1} u^{\prime 2}(t) f^{\prime}(u(t))}{f^{2}(u(t))} R\left(t, t_{0}\right)+\frac{\psi(u(t))\left|u^{\prime}(t)\right|^{\alpha-1} u^{\prime}(t)}{f(u(t))} .
\end{aligned}
$$


From $\left(\mathrm{H}_{1}\right)$ and the definition of $w(t)$, we have

$$
\begin{aligned}
w^{\prime}(t) \leq & \frac{\alpha \rho^{\prime}(t)}{\rho(t)}|w(t)|-k \frac{|w(t)|^{1+\frac{1}{\alpha}}}{\rho(t)(r(t))^{\frac{1}{\alpha}}\left(R\left(t, t_{0}\right)\right)^{\frac{1}{\alpha}}} \\
& -\rho^{\alpha}(t)(q(t)-p(t)) R\left(t, t_{0}\right)+\frac{\psi(u(t))\left|u^{\prime}(t)\right|^{\alpha-1} u^{\prime}(t)}{f(u(t))} .
\end{aligned}
$$

Applying inequality (8), first two term in the second hand side, we get

$$
w^{\prime}(t) \leq-\rho^{\alpha}(t) R\left(t, t_{0}\right)\left[q(t)-p(t)-\mu r(t)\left(\frac{\rho^{\prime}(t)}{\rho(t)}\right)^{\alpha+1}\right]+\frac{\psi(u(t))\left|u^{\prime}(t)\right|^{\alpha-1} u^{\prime}(t)}{f(u(t))}
$$

Case 1: Suppose that $u^{\prime}(t)>0$ for $t \geq t_{1} \geq t_{0}$. An integration of (26) from $t_{1}$ to $t$ yields

$$
w(t) \leq w\left(t_{1}\right)-\int_{t_{1}}^{t} A(s) R\left(s, t_{0}\right) d s+L^{\alpha-1} \int_{u\left(t_{1}\right)}^{u(t)} \frac{\psi(y)}{f(y)} d y .
$$

By $(25)$ and $\left(\mathrm{H}_{5}\right)$, the right side of (27) tends to $-\infty$ as $t \rightarrow \infty$. However, the left side of (27) is nonnegative.

Case 2: Suppose that $u^{\prime}(t)$ oscillates. Then there exists a sequence $\left(\alpha_{n}\right) \rightarrow \infty$ in $I$ such that $u^{\prime}\left(\alpha_{n}\right)=0$. Choose $N$ large enough, so that $\alpha_{N} \geq t_{0}$. With no loss of generality, we assume that $u^{\prime}(t)>0$ for the $\left(\alpha_{N}, \alpha_{N+1}\right)$. Further, in view of (18), we have

$$
\int_{\alpha_{N}}^{\alpha_{N+1}} A(s) R\left(s, t_{0}\right) d s>\epsilon>0
$$

Now, an integration of (26) from $\alpha_{N}$ to $\alpha_{N+1}$, provides

$$
\int_{\alpha_{N}}^{\alpha_{N+1}} A(s) R\left(s, t_{0}\right) d s \leq L^{\alpha-1} \int_{\alpha_{N}}^{\alpha_{N+1}} \frac{\psi(u(s)) u^{\prime}(s)}{f(u(s))} d s .
$$

There are infinite number of $N^{\prime}$ 's such that $u^{\prime}(t)>0$ for $t \in\left(\alpha_{N}, \alpha_{N+1}\right)$. Summing all these inequalities (29), we have

$$
\sum_{k=1}^{\infty} \int_{\alpha_{N}}^{\alpha_{N+1}} A(s) R\left(s, t_{0}\right) d s \leq L^{\alpha-1} \sum_{k=1}^{\infty} \int_{u\left(N_{k}\right)}^{u\left(N_{k+1}\right)} \frac{\psi(y)}{f(y)} d y
$$

In view of (29), the left side of (30) is infinite, whereas the right side of (30) is finite by $\left(\mathrm{H}_{5}\right)$.

Case 3: Suppose that $u^{\prime}(t)<0$ for $t \geq t_{1} \geq t_{0}$. In view of (25), we may assume that there exists $t_{2} \geq t_{1}$, so that

$$
\int_{t_{2}}^{t} \rho^{\alpha}(s)(q(s)-p(s)) R\left(s, t_{1}\right) d s \geq 0, \quad t \geq t_{2} .
$$

Multiplying (1) by $\rho^{\alpha}(t) R\left(t, t_{1}\right)$ and using $\left(\mathrm{H}_{3}\right)$, we get

$$
\rho^{\alpha}(t) R\left(t, t_{1}\right)\left(r(t)\left|u^{\prime}(t)\right|^{\alpha-1} u^{\prime}(t)\right)^{\prime} \leq-\rho^{\alpha}(t) R\left(t, t_{1}\right)(q(t)-p(t)) f(u(t)) .
$$

The rest of the proof is as in the proof of Theorem 2.1. Hence we omit it. 
Note that it can be easily seen from the proof of Theorem 2.4 when $\alpha=1$, it is not necessary to assume that $u^{\prime}(t)$ is bounded. In this case, conclusion of Theorem 2.4 leads to the following results.

Corollary 2.2 Let conditions $\left(\mathrm{H}_{1}\right),\left(\mathrm{H}_{2}\right),\left(\mathrm{H}_{3}\right)$ and $\left(\mathrm{H}_{5}\right)$ hold. Suppose that there exists a differentiable function $\rho: I \rightarrow \mathbb{R}^{+}$such that $\rho^{\prime}(t) \geq 0$ on I. If

$$
\lim _{t \rightarrow \infty} \int_{t_{0}}^{t} \frac{d s}{\rho(s) r(s)}=\infty
$$

and

$$
\limsup _{t \rightarrow \infty} \int_{t_{0}}^{t} \rho(s)\left(\int_{t_{0}}^{s} \frac{d \tau}{\rho(\tau) r(\tau)}\right)\left[q(s)-p(s)-\frac{1}{4 k} r(s)\left(\frac{\rho^{\prime}(s)}{\rho(s)}\right)^{2}\right] d s=\infty,
$$

then Equation (1) is oscillatory.

Remark 2.3 If we take $\rho(t)=1$ in our results, then condition $\left(\mathrm{H}_{1}\right)$ may include weaker conditions. In fact, if we replace condition $\left(\mathrm{H}_{1}\right)$ with the condition $f^{\prime}(x) \geq 0$, then all oscillation criteria above are valid with $\rho(t)=1$. Hence when $\rho(t)=1$ and $\psi(u) \equiv 1$, Theorem 2.1, Theorem 2.2 and Corollary 2.2 reduce to Theorem 2.1 and Theorem 2.2 and Theorem 2.9 in [33], respectively. When $\alpha=1, \psi(u) \equiv 1$ and $\rho(t)=1$, Theorem 2.2 and Corollary 2.2 give Theorem 1 and Theorem 2 in [22], respectively. When $\alpha=1$ and $\rho(t)=1$, Theorem 2.2 and Corollary 2.2 reduce Theorem 1 and Theorem 2 in [2], respectively.

By taking $\left(\mathrm{H}_{4}\right)$ instead of $\left(\mathrm{H}_{3}\right)$, we obtain the following interesting result, which can be applied, for example, to damped half-linear-type equations:

$$
\left(r(t)\left|u^{\prime}(t)\right|^{\alpha-1} u^{\prime}(t)\right)^{\prime}+b(t)\left|u^{\prime}(t)\right|^{\alpha-1} u^{\prime}(t)+q(t) f(u)=0, \quad t \geq t_{0} \geq 0 .
$$

Theorem 2.5 Let conditions $\left(\mathrm{H}_{1}\right),\left(\mathrm{H}_{2}\right)$ and $\left(\mathrm{H}_{4}\right)$ hold. If there exists a differentiable function $\rho: I \rightarrow \mathbb{R}^{+}$such that $\rho^{\prime}(t) \geq 0$,

$$
\lim _{t \rightarrow \infty} \int_{t_{0}}^{t}\left(\frac{e^{-\int_{t_{0}}^{s} \frac{p(\tau)}{r(\tau)} d \tau}}{\rho^{\alpha}(s) r(s)}\right)^{\frac{1}{\alpha}} d s=\infty
$$

and

$$
\limsup _{t \rightarrow \infty} \int_{t_{0}}^{t} C(s) d s=\infty
$$

where

$$
C(t)=\rho^{\alpha}(t)\left[q(t)-\mu_{1} r(t)\left|\frac{\alpha \rho^{\prime}(t)}{\rho(t)}+\frac{p(t)}{r(t)}\right|^{\alpha+1}\right] \quad \text { and } \quad \mu_{1}:=\frac{1}{(\alpha+1)^{\alpha+1}}\left(\frac{\alpha}{k}\right)^{\alpha} \text {, }
$$

then Equation (1) with $\psi(u) \equiv 1$ is oscillatory. 
Proof To the contrary, let $u(t)$ be a nonoscillatory solution of (1). We may assume that $u(t)>0$ for $t \geq t_{1} \geq t_{0}$. The proof in the case $u(t)<0$ for $t \geq t_{1}$ is similar and hence omitted. Differentiating (5) and making use of (1) and from hypotheses $\left(\mathrm{H}_{1}\right),\left(\mathrm{H}_{2}\right),\left(\mathrm{H}_{4}\right)$ and $(8)$, as in the proof of Theorem 2.1, we can obtain easily that

$$
w^{\prime}(t) \leq-\rho^{\alpha}(t)\left[q(t)-\mu_{1} r(t)\left|\frac{\alpha \rho^{\prime}(t)}{\rho(t)}+\frac{p(t)}{r(t)}\right|^{\alpha+1}\right] .
$$

Integrating this inequality from $t_{1}$ to $t$, we get

$$
w(t) \leq w\left(t_{1}\right)-\int_{t_{1}}^{t} \rho^{\alpha}(s)\left[q(s)-\mu_{1} r(s)\left|\frac{\alpha \rho^{\prime}(s)}{\rho(s)}+\frac{p(s)}{r(s)}\right|^{\alpha+1}\right] d s, \quad t \geq t_{1} \geq t_{0} .
$$

Letting $\lim \sup _{t \rightarrow \infty}$, we get in view of (3) that $w(t) \rightarrow-\infty$. Hence, there exists $t_{2} \geq t_{1}$ such that $u^{\prime}(t)<0$ for $t \geq t_{2}$. Condition (34) also implies that

$$
\int_{t_{0}}^{\infty} \rho^{\alpha}(s) q(s) d s=\infty
$$

and there exists $t_{3} \geq t_{2}$ such that

$$
\int_{t_{3}}^{t} \rho^{\alpha}(s) q(s) d s \geq 0
$$

for $t \geq t_{3}$. Proceeding similarly as in Theorem 2.1, using condition (33), we obtain a contradiction.

As an immediate consequence of Theorem 2.5, we have the following interesting criteria for the oscillation of (1).

Corollary 2.3 Let condition (34) in Theorem 2.5 be replaced by

$$
\limsup _{t \rightarrow \infty} \int_{t_{0}}^{t} \rho^{\alpha}(s) q(s) d s=\infty
$$

and

$$
\int_{t_{0}}^{\infty} \rho^{\alpha}(s) r(s)\left|\frac{\alpha \rho^{\prime}(s)}{\rho(s)}+\frac{p(s)}{r(s)}\right|^{\alpha+1} d s<\infty .
$$

Then the conclusion Theorem 2.5 holds.

It is clear that condition (38) is a necessary condition for (34) to hold.

In case (34) failed to be satisfied that the following theorem may be applicable.

Theorem 2.6 Let conditions $\left(\mathrm{H}_{1}\right),\left(\mathrm{H}_{2}\right),\left(\mathrm{H}_{4}\right)$ and $\left(\mathrm{H}_{5}\right)$ hold. Suppose that $\rho$ is a positive continuously differentiable function on the interval I such that $\rho^{\prime}(t) \geq 0$ on I and (34) hold. If

$$
\int_{t_{0}}^{\infty} \rho^{\alpha}(t) q(t) d t<\infty
$$


and

$$
\begin{aligned}
& \liminf _{t \rightarrow \infty} \int_{t_{0}}^{t} C(s) d s \geq 0, \\
& \lim _{t \rightarrow \infty} \int_{t_{0}}^{t}\left(\frac{1}{\rho^{\alpha}(s) r(s)} \int_{s}^{\infty} C(u) d u\right)^{\frac{1}{\alpha}} d s=\infty,
\end{aligned}
$$

then Equation (1) with $\psi(u) \equiv 1$ is oscillatory.

Proof Proof is a similar to the proof of Theorem 2.2.

Remark 2.4 If we take $f(u)=|u|^{\alpha-1} u$, then $\frac{f^{\prime}(u)}{|f(u)|^{1-\frac{1}{\alpha}}}=k=\alpha$ is satisfied. Therefore, all above oscillation criteria are valid for the half-linear equation

$$
\left(r(t)\left|u^{\prime}\right|^{\alpha-1} u^{\prime}\right)^{\prime}+q(t)|u|^{\alpha-1} u=0 .
$$

Remark 2.5 More recently, Ouyang and et al. [17] gave some oscillation criteria for Equation (32) under the main condition $f^{\prime}(x) \geq 0$. However, their results impose sign conditions on function $b(t)$ and $q(t)$. In our results, we assume that hypothesis $\left(\mathrm{H}_{1}\right)$ is stronger than $f^{\prime}(x) \geq 0$. But our results do not depend on signs of the functions $b(t)$ and $q(t)$. Note that Theorem 3.6 given in [26], which also does not depend on the signs of $b(t)$ and $q(t)$, is different from Theorem 2.5 above, because it contains suitable averaging functions.

\section{Competing interests}

The authors declare that they have no competing interests.

\section{Authors' contributions}

All authors completed the paper together. All authors read and approved the final manuscript.

\section{Author details}

${ }^{1}$ Department of Mathematics, Faculty of Science, Erciyes University, Kayseri, Turkey. ${ }^{2}$ Department of Mathematics and Computer Science, Faculty of Art and Sciences, Izmir University, Uckuyular, Izmir, 35350, Turkey.

\section{Acknowledgements}

The authors would like to express their thanks to the anonymous referee for his(her) valuable suggestions and comments on the manuscript of this paper

Received: 15 February 2013 Accepted: 20 September 2013 Published: 11 Nov 2013

\section{References}

1. Agarwal, RP, Avramescu, C, Mustafa, OG: On the oscillation theory of a second-order strictly sublinear differential equation. Can. Math. Bull. 53(2), 193-203 (2010)

2. Zhang, Q, Wang, L: Oscillatory behavior of solutions for a class of second-order nonlinear differential equation with perturbation. Acta Appl. Math. 110, 885-893 (2010)

3. Agarwal, RP, Grace, SR, O'Regan, D: Oscillation Theory for Difference and Functional Differential Equations. Kluwer, Dordrecht (2000)

4. Agarwal, RP, Grace, SR, O'Regan, D: Oscillation Theory for Second-Order Linear, Half Linear, Superlinear, Sublinear, Dynamic Equations. Kluwer, Dordrecht (2002)

5. Ladde, GS, Lakshmikantham, V, Zhang, BG: Oscillation Theory of Differential Equations with Deviating Arguments. Dekker, New York (1987)

6. Yan, J: Oscillation Theory of Ordinary Differential Equations. Shanxi Education Press, Taiyuan (1992)

7. Ayanlar, B, Tiryaki, A: Oscillation theorems for nonlinear second-order differential equations. Comput. Math. Appl. 44, 529-538 (2002)

8. Butler, GJ: Integral averages and the oscillation of second-order differential equations. SIAM J. Math. Anal. 11, 190-200 (1980)

9. Coles, WJ: An oscillation criterion for the second-order equations. Proc. Am. Math. Soc. 19, 755-759 (1968)

10. Coles, WJ: Oscillation criteria for nonlinear second-order equations. Ann. Mat. Pura Appl. 8282, 132-134 (1969) 
11. Elabbasy, EM, Hassan, TS, Saker, SH: Oscillation of second-order nonlinear differential equations with damping term. Electron. J. Differ. Equ. 2005(76), 1-13 (2005)

12. Graef, JR, Spikes, PW: On the oscillatory behavior of solutions of second-order non-linear differential equations. Czechoslov. Math. J. 36, 275-284 (1986)

13. Graef, JR, Rankin, SM, Spikes, PW: Oscillation theorems for perturbed non-linear differential equation. J. Math. Anal. Appl. 65, 375-390 (1978)

14. Hong, HL: On the oscillatory behavior of second-order non-linear differential equations. Publ. Math. (Debr.) 52, 55-68 (1998)

15. Kwang, MK, Wong, JSW: An application of integral inequality to second-order non-linear oscillation. J. Differ. Equ. 46, 63-67 (1992)

16. Kamenev, IV: An integral criterion for oscillation of linear differential equation of second-order. Mat. Zametki 23 249-251 (1978)

17. Ouyang, Z, Zhong, J, Zou, S: Oscillation criteria for a class of second-order nonlinear differential equations with damping term. Abstr. Appl. Anal. 2009, 1-12 (2009)

18. Philos, CHG: Oscillation criteria for second-order superlinear differential equations. Can. J. Math. XLI(2), 321-340 (1989)

19. Philos, CHG: Oscillation theorems for linear differential equation of second-order. Arch. Math. 53, 483-492 (1989)

20. Philos, CHG: An oscillation criterion for superlinear differential equations of second-order. J. Math. Anal. Appl. 148(2), 306-316 (1990)

21. Philos, CHG: Integral averages and oscillation of second-order sublinear differential equations. Differ. Integral Equ. 4(1), 205-213 (1991)

22. Remili, M: Oscillation criteria for second-order nonlinear perturbed differential equations. Electron. J. Qual. Theory Differ. Equ. 25, 1-11 (2010)

23. Sun, YG: New Kamenev-type oscillation criteria for second-order nonlinear differential equations with damping. J. Math. Anal. Appl. 291, 341-351 (2004)

24. Tiryaki, A, Cakmak, D, Ayanlar, B: On the oscillation of certain second-order nonlinear differential equations. J. Math. Anal. Appl. 281, 565-574 (2003)

25. Tiryaki, A, Zafer, A: Interval oscillation of a general class of second-order nonlinear equations with nonlinear damping Nonlinear Anal. 60, 49-63 (2005)

26. Tiryaki, A, Basci, Y: Oscillation theorems for certain even-order nonlinear damped differential equations. Rocky Mt. J. Math. 38(3), 1011-1035 (2008)

27. Tiryaki, A: Oscillation criteria for a certain second-order nonlinear differential equations with deviating arguments, Electron. J. Qual. Theory Differ. Equ. 61, 1-11 (2009)

28. Wong. JSW: Oscillation theorems for second-order nonlinear differential equations. Bull. Inst. Math. Acad. Sin. 3 , 263-309 (1975)

29. Wong, PJY, Agarwal, RP: Oscillatory behavior of solutions of certain second-order nonlinear differential equations, J. Math. Anal. Appl. 198, 297-354 (1996)

30. Wong, PJY, Agarwal, RP: Oscillation criteria for half-linear differential equations. Adv. Math. Sci. Appl. 9(2), 649-663 (1999)

31. Yeh, CC: Oscillation theorems for nonlinear second-order differential equations with damped term. Proc. Am. Math. Soc. 84, 397-402 (1982)

32. Xu, Z, Xia, Y: Kamenev-type oscillation criteria for second-order quasilinear differential equations. Electron. J. Differ. Equ. 2005(27), 1-9 (2005)

33. Wong, PJY, Agarwal, RP: The oscillation and asymptotically monotone solutions of second-order quasi linear differential equations. Appl. Math. Comput. 79, 207-237 (1996)

34. Yeh, CC: An oscillation criterion for second-order nonlinear differential equations with functional arguments. J. Math. Anal. Appl. 76, 72-76 (1980)

35. Ayanlar, B, Tiryaki, A: Oscillation theorems for nonlinear second-order differential equations with damping. Acta Math. Hung. 89(1-2), 1-13 (2000)

$10.1186 / 1029-242 X-2013-524$

Cite this article as: Temtek and Tiryaki: Oscillation criteria for a certain second-order nonlinear perturbed differential equations. Journal of Inequalities and Applications 2013, 2013:524

\section{Submit your manuscript to a SpringerOpen ${ }^{\ominus}$ journal and benefit from:}

- Convenient online submission

Rigorous peer review

- Immediate publication on acceptance

Open access: articles freely available online

- High visibility within the field

- Retaining the copyright to your article 